\title{
IMPLEMENTASI E-COMMERCE MENGGGUNAKAN CONTENT MANAGEMENT SYSTEM (CMS) PADA TOKO THANKSGOD DALAM UPAYA MEMPERLUAS AREA PEMASARAN
}

\author{
Angga Subekti Hadi Prayitno ${ }^{1)}$, Joko Sutrisno ${ }^{2)}$ \\ ${ }^{1}$ Sistem Informasi, Fakultas Teknologi Informasi, Universitas Budi Luhur \\ 1,2Jl. Raya Ciledug, Petukangan Utara, Kebayoran Lama, Jakarta Selatan 12260 \\ E-mail : anggasubekti.ap@gmail.com ${ }^{1)}$, joko.sutrisno@budiluhur.ac.id ${ }^{2}{ }^{2}$
}

\begin{abstract}
Abstrak
E-commerce adalah salah satu teknologi didalam dunia internet khususnya pada bidang pemasaran. Ecommerce menemukan cara baru yaitu didalam dunia informasi, sehingga memberikan informasi dalam bentuk yang menarik dan bisa diakses setiap saat secara online, kapanpun dan dimana saja. Toko ThanksGod menjual produk yang mempunyai kualitas sangat bagus. Dalam melakukan kegiatannya, Toko ThanksGod masih menggunakan media penyampaian informasi yang sederhana sehingga untuk pemasaran produk dan layanannya masih belum maksimal. Dengan masalah yang dihadapi oleh Toko ThanksGod, maka dibutuhkan sebuah sistem informasi berbasis website,Thanksgod yang bergerak dibidang penjualan dalam bidang topi, jaket dan tas. Menjual berbagai macam produk yang berkualitas unggul dan baik. Kurangnya pemasaran produk-produk dan penanganan order pada toko ThanksGod dari permasalahan tersebut maka dapat disimpulkan untuk dibuatnya website e-commerce berbasis CMS (Content Management System). Pendekatan yang dilakukan oleh peneliti yaitu wawancara, observasi, dan studi literatur. Hasil dari penelitian ini yaitu website berbasis CMS (Content Management System) yang bisa membantu meningkatnya omset pendapatan, mudahnya dalam mencari informasi produk dan memperluas jangkauan area penjualan.
\end{abstract}

Kata kunci: Website, E-Commerce, Content Management System, Thanksgod, Topi, Jaket, Tas

\section{PENDAHULUAN}

Pengertian E-commerce merupakan proses jual beli produk secara elektronik untuk konsumen, perusahaan ke perusahaan dengan komputer sebagai penghubung transasksi bisnis.[1]Dan Manfaat ECommerce adalah kemudahan belanja kebutuhan dalam 24 jam tanpa adanya kontak secara langsung seperti layaknya bertransaksi secara tradisional [2]. Dengan adanya e-commerce bisa memperluas area pemasaran. Adapun tujuan penulisan yang dilakukan dalam penelitian saya yaitu Website e-commerce untuk meningkatkan dan mengembangkan penyebaran produk secara online pada toko ThanksGod. Dan Website e-commerce bisa memaksimalkan penanganan order pada toko ThanksGod. Adapun permasalahan yang terjadi pada Toko ThanksGod Kurangnya pemasaran produkproduk pada Toko ThanksGod yang berdampak pada penurunan pendapatan dan belum maksimalnya penanganan order yang terjadi pada toko ThanksGod

\section{PENELITIAN SEBELUMNYA}

Menurut Penelitian [3] yang berjudul "Pengembangan Bisnis Sandiwara Store Dengan Menggunakan Pendekatan Bussines Canvas Model”. Sandiwara Store adalah sebuah toko yang penjualannya di bidang fashion dan pakaiannya bertemakan music/ film. Sehingga Sansiwara Store mempunyai masalah pada masa produksi hingga penjualan, sehingga menyebabkan tidak maksimalnya pendapatan yang bisa di dapat oleh Sandiwara Store. Maka dari itu dibutuhkan adanya sebuah model bisnis dari Sandiwara Store untuk membantu memperjelas bagian-bagian apa saja yang bisa membantu Sandiwara Store dalam kelangsungan produksi dan penjualannya. Business Model Canvas adalah alat bantu yang digunakan dalam memetakan sembilan blok elemen yang terhubung dengan Sandiwara Store baik pada masa produksi maupun masa penjualan. Sembilan blok elemen yang ada pada Business Canvas ialah Customer Segments, Value Propositions, Channels, Customer Relationships, Revenue Streams, KeyPartnerships, dan Key Resources.Sembilan blok elemen tersebut didapat setelah mengolah data yang diambil dari perusahaan kompetitor dan perusahaanpemimpin pasar. Analisis SWOT dilakukan untuk mengetahui kekuatan, kelemahan, peluang, dan ancaman yang ada pada sembilan blok elemen Sandiwara Store. Menurut penelitian [4] yang berjudul "Perancangan dan Penerapan "Search Engine Optimization "(SEO) Pada Website Pemasaran Produk Toko Janjebles” yaitu Toko Janjebles mengalami kesulitan dalam memasarkan produknya. Solusi yang diberikan adalah membuat website, namun untuk mengoptimalkan website juga 
diperlukan teknik tertentu agar web dikenal orang. Namun sayangnya beberapa Toko Janjebles tidak memahami hal tersebut. Oleh karena itu, penelitian ini akan mengimplementasikan teknik agar website Janjebles dikenal oleh mesin pencari. Penelitian ini akan mengimplementasikan website berbasis Search Engine Optimization (SEO) menggunakan teknik On page. Teknik On page dapat dilakukan diantaranya dengan membuat template yang SEO friendly dan cepat saat diakses, memasang meta tag dan keyword. Analisa keyword tentang baju Janjebles akan dilakukan agar produk dapat menempati rangking atas dalam pencarian Google. Hasil dari penelitian ini adalah website Janjebles yang mengimplementasikan SEO On page dengan cara yang mudah. Penggunaan Content Management System diharapkan dapat membantu pengelola web untuk mempromosikan produknya dan berakibat pada peningkatan penjualan produk Toko Janjebles tersebut.

\section{METODE PENELITIAN}

\subsection{Pendekatan Penelitian}

Pendekatan penelitian yang dilakukan oleh peneliti untuk mengumpulkan data yaitu wawancara, oberservasi, analisa dokumen, studi literature berikut penjelasan tentang pendeketan penelitian tersebut yaitu :

a. Wawancara

Pada tahap ini penulis mengajukan pertanyaanpertanyaan menyangkut Toko ThanksGod kepada Pak Izhar Mulky selaku pemilik Toko ThanksGod. Pada tahap ini penulis mendapatkan bagaimana arus proses bisnis penjualan pada Toko ThanksGod.

b. Observasi

Pada tahap ini penulis datang dan meninjau langsung ke toko ThanksGod yang beralamat di Jl. Kh Wahid Hasyim Kreo Selatan, Tangerang. Dan penulis dapat melakukan pengamatan bagaimana proses penjualan yang terjadi di Toko ThanksGod.

c. Analisa dokumen

Proses yang dilakukan dengan cara membuat dokumen dari semua catatan, nota, dan beberapa laporan di Toko ThanksGod.

d. Studi Literatur

Penelitian ini dilakukan penulis yang didapat dari acuan jurnal yang didapat dari berbagai sumbersumber yang ada di internet maupun buku-buku yang ada diperpustakaan.

\subsection{Teknik Analisis Data}

a. Analisa Proses Bisnis

Dilakukan dengan beberapa cara yang diambil dari proses bisnis berjalan didalam penelitian.

b. Analisa Masalah
Dilakukan dari bebarapa cara yaitu termasuk dari observasi dan wawancara serta menguraikan masalah yang terjadi pada Toko ThanksGod.

c. Analisa Kebutuhan

Digunakan setelah didapatkan permasalahan yang ada pada Toko ThanksGod. Kemudian permasalahan itu dibuatkan solusi dengan mengidentifikasi kebutuhan apa saja yang dibutuhkan dan di gambarkan dengan Class Diagram, Use Case Diagram, System Sequence Diagram.

\subsection{Tools Yang Digunakan}

a. SEO (Search Engine Optimization)

Menurut [5] SEO (Search Engine Optimization) adalah sebuah proses yang menggunakan prinsip-prinsip dasar pencarian dari sebuah mesin pencari untuk mendapatkan dan juga meningkatkan nilai indeks peringkat yang lebih tinggi untuk sebuah halaman website atau juga dapat digunakan untuk meningkatkan jumlah akses kunjungan.

b. Website

Menurut [6] Website adalah kumpulan dari halaman web yang sudah dipublikasikan di jaringan internet dan memiliki domain yang dapat diakses semua pengguna internet dengan cara mengetikan alamatnya.

c. CMS (Content Management System)

Menurut [7] CMS (Content Management System) merupakan sebuah sistem yang digunakan untuk mengelola proses pembuatan, pembaharuan dan publikasi konten secara bersama, yang mengacu pada informasi dalam bentuk teks, grafik, gambar maupun dalam format-format lain yang perlu dikelola.

d. Wordpress

Menurut [8] Wordpress adalah sebuah perangkat lunak yang digunakan untuk membuat website. Namun tidak hanya web pribadi dan situs berita, tetapi bisa dijadikan toko online. Wordpress ini sudah sangat popular untuk digunakan sebagai layanan blog.

e. WooCommerce

Menurut [9] WooCommerce adalah sebuah plugin wordpress yang khusus digunakan untuk membuat toko online.

f. Balsamiq

Menurut [10] Balsamiq adalah aplikasi untuk membuat sketsa desain tampilan antarmuka sistem

\section{HASIL DAN PEMBAHASAN}

\subsection{Bussiness Model Canvas}

Gambar 1 merupakan business model canvas pada toko ThanksGod, terdiri dari 9 bagian yang menjelaskan proses-proses bisnis. 


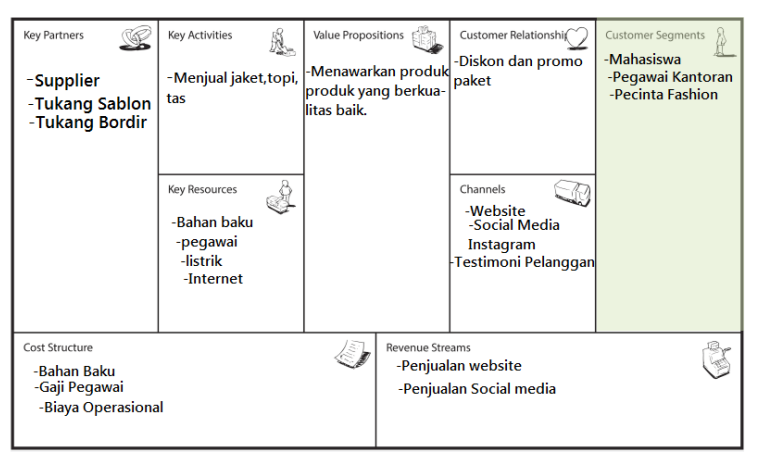

Gambar 1. Bussiness Model Canvas

a. Customer Segments

Target Konsumen pada Toko ThanksGod adalah mahasiswa, pegawai kantoran, dan masyarakat pecinta fashion.

b. Value Propositions

Merupakan nilai yang produsen tawarkan kepada konsumen. Menawarkan produk seperti jaket, tas dan topi.

c. Channels

Pemasaran Produk Toko ThanksGod melalui website, social media marketing melalui Instagram dan WhatsApp.

d. Customer Relationships

Beberapa cara produsen untuk terus berhubunan dengan konsumen. Toko ThanksGod mengadakan diskon dan promo paket secara berkala.

e. Revenue Streams

Cara produsen mendapatkan keuntungan dari value proposition. Keuntungan Toko ThanksGod didapat dari hasil penjualan di social media dan pemesanan online baik dari website.

f. Key Activities

Aktivitas utama yang berkaitan dengan sebuah penjualan di toko ThanksGod yaitu menjual jaket, tas dan topi .

g. Key Resources

Berbagai Sumber Daya yang dapat membantu memajukan penjualan pada Toko ThanksGod adalah bahan baku, pegawai, listrik dan internet.

h. Key Partnerships

Berbagai pihak yang membantu toko ThanksGod dapat mengsukseskan dan memudahkan aktivitas bisnis. adalah supplier dan tukang sablon, tukang border.

i. Cost Structure

Pengeluaran yang dapat membantu untuk mengsukseskan bisnis ini. Yaitu bahan baku, gaji pegawai, dan biaya operasional.

\subsection{Activity Diagram}

Gambar 2 merupakan activity diagram proses pembayaran diawali pelanggan melakukan pembayaran ke rekening bank yang terdapat pada halaman detail order setelah melakukan Checkout.
Setelah melakukan transfer, lalu Login website dan masuk ke menu Confirm Payment dan pelanggan mengisi form checking payment yang ada di menu pembayaran dan mengupload Bukti transfer. Kemudian admin menerima email konfirmasi pembayaran yang telah dilakukan oleh pelanggan, lalu admin melakukan verifikasi konfirmasi pembayaran di halaman backend website dan pelanggan menerima email bahwa sudah melakukan pembayaran.

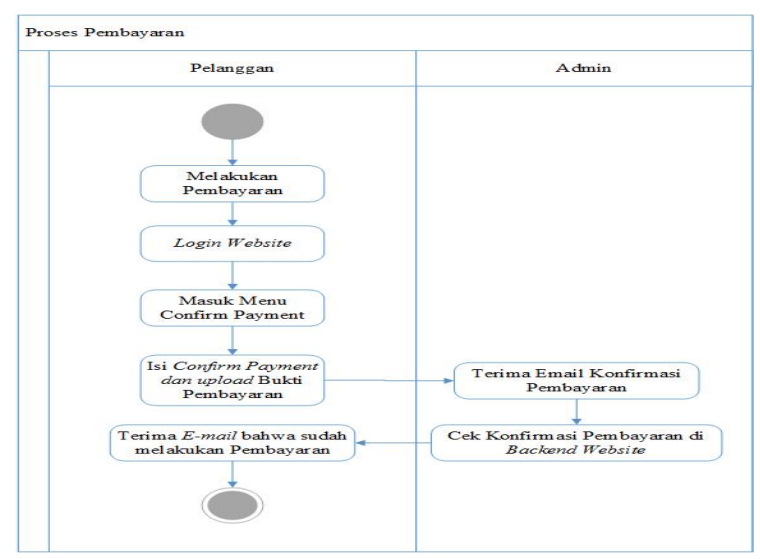

Gambar 2. Activity Diagram Proses Pemesanan

\subsection{Use Case Diagram}

Gambar 3 adalah use case diagram master, dimana pelanggan dapat melakukan pendaftaran kemudian pelanggan mendapatkan notifikasi email pendaftaran, dan admin dapat input produk beserta produk kategori.

\section{a. Use Case Diagram Master}

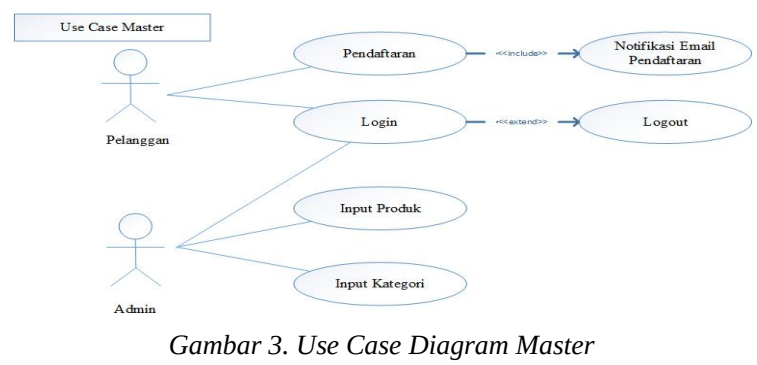

b. Use Case Diagram Transaksi

Gambar 4 yaitu use case diagram transaksi, terdapat 2 actor yaitu pelanggan dan admin, pelanggan melakukan pemesanan dan konfirmasi pembayaran, dari sisi admin dapat melakukan verifikasi pembayaran serta input nomor resi pengiriman, dan admin ganti status order lalu pelanggan dan admin akan mendapatkan email pembayaran. 


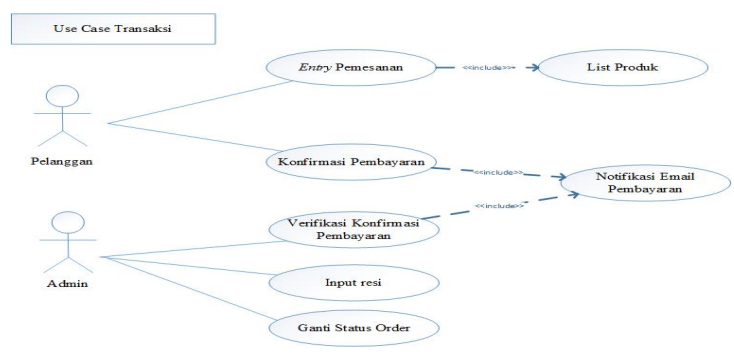

Gambar 4. Use Case Diagram Transaksi

c. Use Case Diagram Laporan

Gambar 5 merupakan use case diagram laporan. Hanya ada 2 actor yaitu admin dan direksi, admin dapat mencetak laporan pemesanan, laporan penjualan, laporan pengiriman, laporan pembayaran, laporan rekapitulasi produk terlaris dan kemudian memberikan kepada pemilik toko.
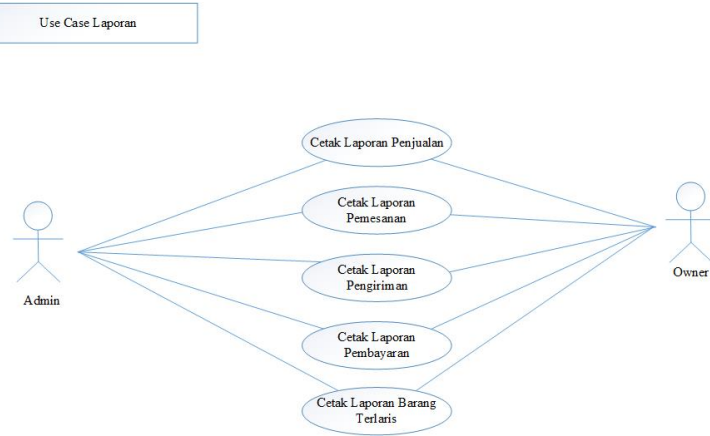

Gambar 5. Use Case Diagram Laporan

\subsection{Struktur Tampilan}

a. Struktur Tampilan Menu Pelanggan

Gambar 6 memperlihatkan struktur tampilan menu pelanggan pada website ThanksGod.

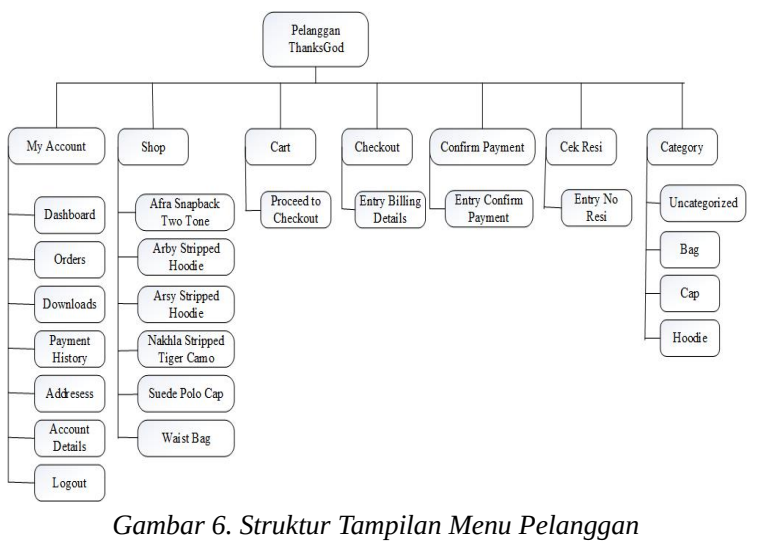

b. Struktur Tampilan Menu Admin

Gambar 7 yaitu Struktur Tampilan Menu Admin terdapat berbagai menu didalamnya dan menu ini di rancang untuk mempermuudahkan penggunaan dari sisi admin.

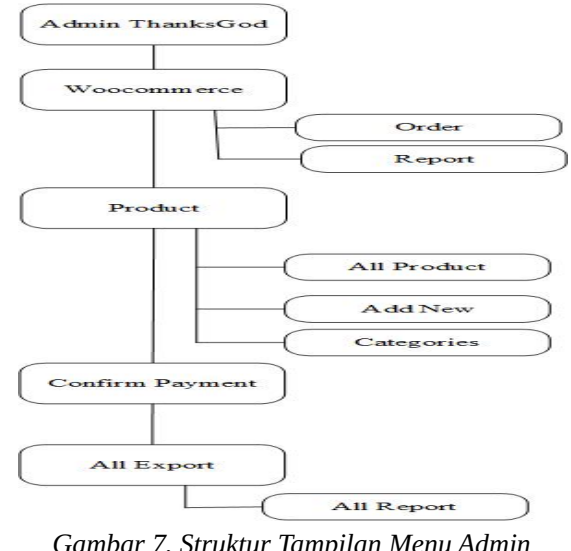

c. Class Diagram

Gambar 8 yaittu class diagram pada yang terdapat dari website Thanksgod
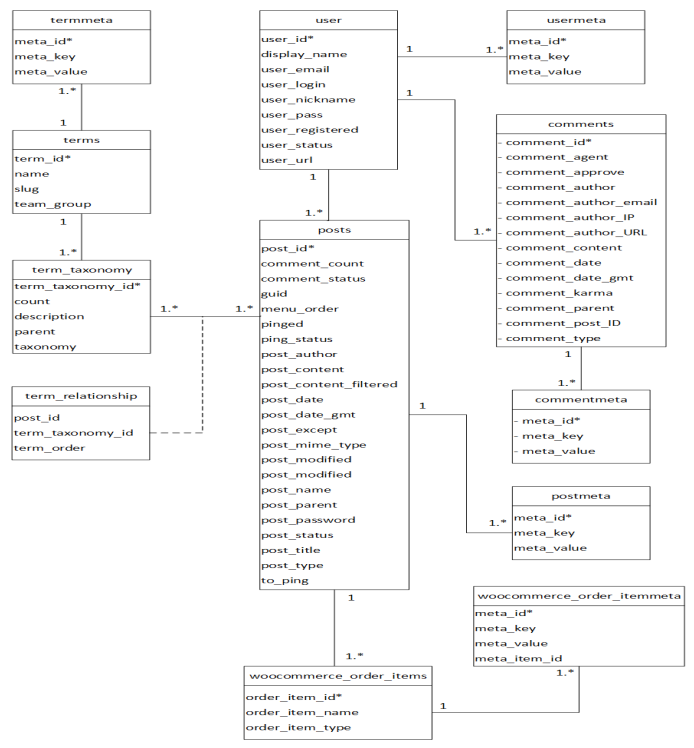

Gambar 8. Class Diagram

\subsection{Rancangan Layar}

a. Rancangan Layar Shop

Gambar 9 adalah rancangan layar shop yang menampilkan semua produk yang sudah ditampilkam dan akan dipilih produknya .

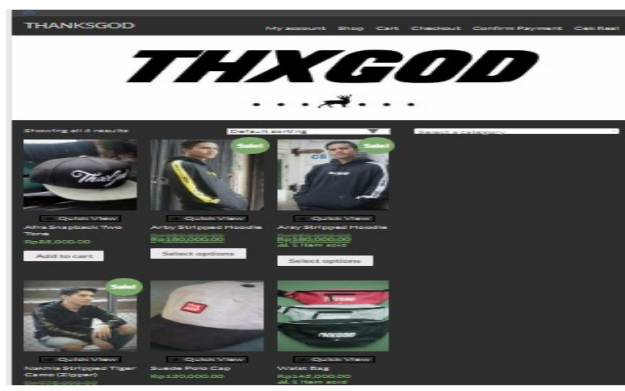

Gambar 9. Rancangan Layar Shop 
b. Rancangan Layar Cart

Gambar 10 yaitu rancangan layar cart yang memperlihatkan semua produk yang sudah berhasil dimasukan kedalam keranjang belanja setelah pelanggan memilih produk dan ukuran produk untuk selanjutnya masuk untuk checkout.

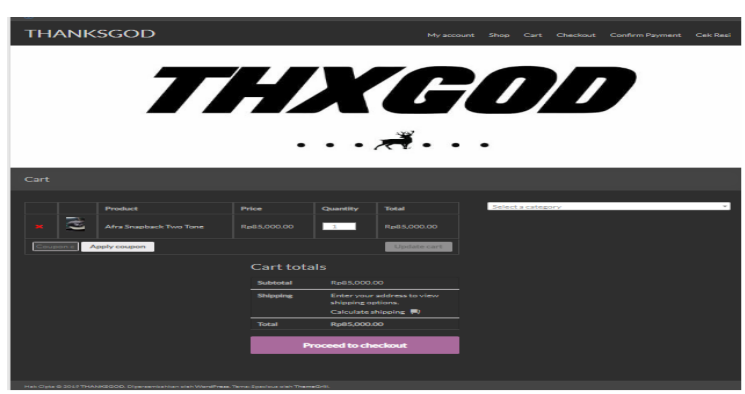

Gambar 10. Rancangan Layar Cart

c. Rancangan Layar Checkout

Gambar 11 merupakan rancangan layar Checkout. Pelanggan akan melengkapi dan mengisi Billing Details. Yang akan menentukan berap biaya total pengiriman dari harga profuk beserta biaya pengirimannya

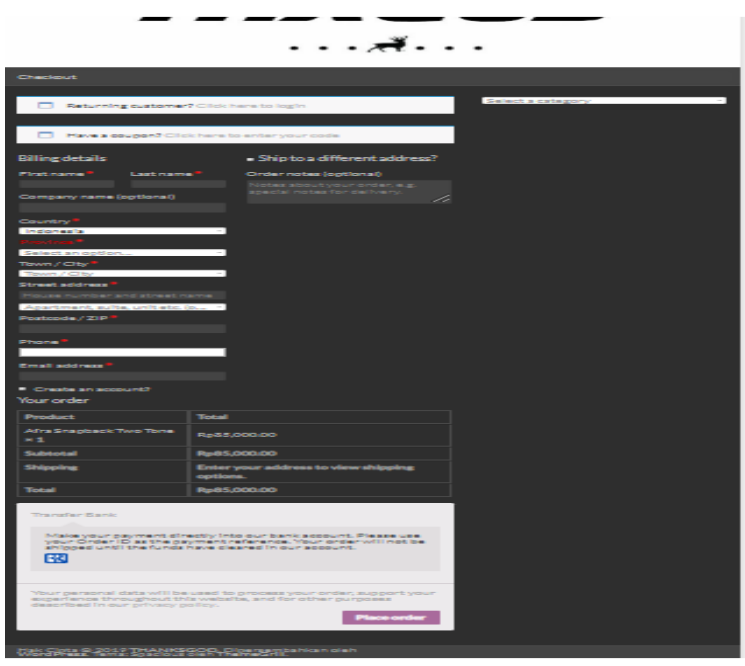

Gambar 11. Rancangan Layar Checkout

\subsection{Keluaran Sistem Usulan}

Gambar 12 merupakan keluaran sistem usulan email order Completed, email akan otomatis terkirim setelah admin merubah status pesanan menjadi completed. Setelah pelenggan telat melengkapi Billing Details di menu checkout dan melakukan pembayaran di menu Confirm Payment

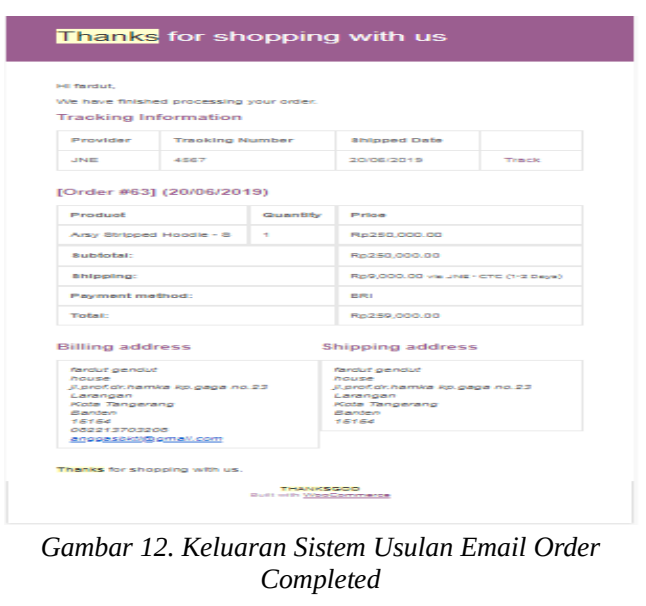

\subsection{System Sequence Diagram}

Gambar 13 merupakan system sequence diagram yang dimulai dari pelanggan memilih menu shop, yang akan muncul ke keranjang lalu memilih produk hingga menginput dan melengkapi billing details dan akan muncul tampilan order details

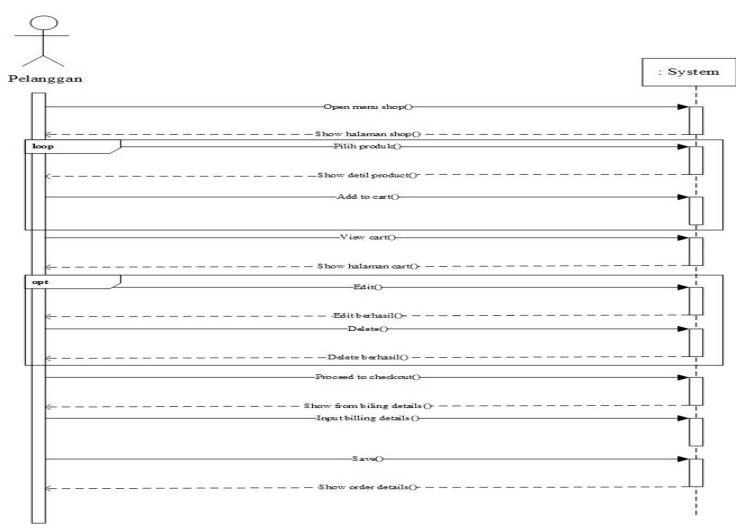

Gambar 13. System Sequence Diagram Entry Pemesanan

\subsection{Strategi SEO dan Marketing}

Berikut adalah strategi SEO yang digunakan yaitu:

1. Install Plugin Yoast SEO

Yoast SEO adalah plugin wordpress untuk membantu dan memudahkan admin untuk dalam hal optimasi SEO website yang menggunakan Content Management System(CMS).

\section{Aktivasi Google Console}

Google Console menyediakan laporan berikut beberapa data yang mampu membantu memahami halaman website sehingga muncul di hasil pencarian kemudian mengetahui search query dari halaman lalu website muncul di hasil pencarian dan seberapa sering di kunjungi.

3. Title Tag 
Title tag adalah judul di suatu dokumen. adanya title tag pengunjung bisa memahami pemahaman yang tersedia dari informasi yang disajikan.

\section{Meta Description}

Meta Description yaitu deskripsi dari pengguna website itu sendiri untuk menjual dari beberapa konten yang disediakan oleh admin kepada pengguna.

5. Focus Keyphrase

membantu mengidentifikasi keyword yang dioptimasi dengan baik, di fitur ini secara otomatis yoast akan mengupdate status ON Page pada website yang dibuat.

7. Hasil SEO

Gambar 14 merupakan hasil dari penerapan SEO pada website ThanksGod

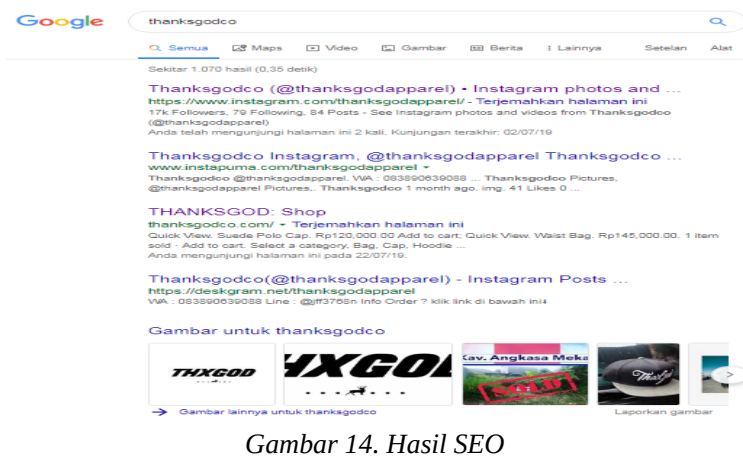

Berikut strategi marketing yang dilakukan untuk meningkatkan daya tariknya:

a. Mengadakan diskon ke beberapa produk.

b. Mengadakan promo disetiap bulannya.

c. Menyantukan alamat website di profile Instagram Thanksgodco

\section{KESIMPULAN}

Kesimpulan yang diambil oleh penulis yaitu :

1. Dengan tersedianya website berbasis ecommerce dengan content management system di ThanksGod dapat memudahkan dalam hal menjual produk secara lebih luas.

2. Dengan adanya E-commerce Menampilkan semua informasi produk yang begitu lengkap dan juga menarik yang diperuntukan untuk pelanggan.

3. Dengan adanya E-commerce Memberitahu mengenai promo-promo bersamaan dengan diskon ditujukan kepada pelanggan.

4. Website yang mudah untuk digunakan (user friendly) baik dari segi pelanggan (front-end) maupun admin (back-end).

5. Dengan adanya E-commerce Dapat memaksimalkan penanganan order untuk
Admin

Saran yang didapat oleh penulis didalam penelitian ini, yaitu:

1. Perlu diadakan pelatihan kepada user selaku admin yang akan menggunakan dan mengelola website ini secara baik.

2. Melakukan pengembangan yang lebih lanjut untuk website, dari segi sitem ataupun informasi yang disajikan di dalamnya.

3. Menambahkan beberapa konten atau produk baru agar lebih menarik bagi para pengunjung website.

\section{DAFTAR PUSTAKA}

[1] Ahluwalia, M. S. et al. E-commerce Sebagai Pendukung Pemasaran, IOSR Journal of Economics and Finance, 3(1), p. 56. 2016.

[2] Heru, M. M. S. R. S. Implementasi E-commerce Sebagai Media Penjualan Online (Studi Kasus Pada Toko Pastbrik Kota Malang), Jurnal Administrasi Bisnis (JAB), 29(1), pp. 1-9. 2015.

[3] Anggoro, D., Budi, P and Rio, A. Pengembangan Model Bisnis Model Sandiwara Store Dengan Menggunakan Pendekatan Business Model Canvas, Prosiding Teknik, 3(2), pp. 3058-3065. 2016.

[4] Hayati, M. and Reno, S. K. Perancangan Dan Penerapan "Search Engine Optimization" (SEO) Pada Website Pemasaran Produk Toko Janjebles, Jurnal Sistem Informasi dan Manajemen Basis Data (SIMADA), 2(1), pp. 40-49. 2019.

[5] Halilintar, R. B. and Ariyus, D. Implementasi Seo ( Search Engine Optimization ) Pada Website Agc ( Auto Generated Content ) Untuk Meningkatkan Serp ( Search Engine Result Page ) Studi Kasus: Website Gallery, Seminar Nasional Teknologi Informasi dan Multimedia, pp. 13-18. 2018.

[6] Nofyat, Adelina Ibrahim, A. A. Sistem Informasi Pengaduan Pelanggan Air Berbasis Website Pada PDAM Kota Ternate, Indonesian Journal on Information System, 3(1), p. 4. 2018.

[7] Elinawati, S. dan Muhammad, A. Perancangan Content Management System (CMS) Dengan Studi Kasus E-Bisnis Pada Toko Alya Gorden, Jurnal KomTekInfo Fakultas Ilmu Komputer, 2(1), pp. 7990. 2015.

[8] Rachmawati, S. D. Sistem Informasi Penjualan Alat Tulis Kantor Berbasis Web Pada Cv.Sumber Rezeki Jakarta, Seminar Nasional Ilmu Pengetahuan dan Teknologi Komputer Nusa Mandiri, pp. 283-288. 2016.

[9] Wahana, A. Rancang Bangun Marketplace Produk Kewirausahaan Mahasiswa UPY Berbasis Content Management System, Jurnal Dinamika Informatika, 7(1), pp. 73-81. 2018.

[10] Setiyani, L. Desain Sistem Manajemen Inventory Produk Farmasi Menggunakan Pendekatan Prototipe, Jurnal Ippmunindra , 11(3), pp. 225-234. 2018. 